\title{
O PAPEL DAS TECNOLIGIAS DA INFORMAÇÃO E COMUNICAÇÃO (TIC) NO CUMPRIMENTO DAS METAS DO PLANO NACIONAL DA EDUCAÇÃO (PNE)
}

Francisca Auderlânia de Oliveira Dias, Instituto Federal de Educação, Ciência e Tecnologia do Ceara (IFCE) audelania_dias@ hotmail.com

Emannuel Diego Gonçalves de Freitas, Instituto Federal de Educação, Ciência e Tecnologia do Ceara (IFCE) diego@ifce.edu.br

\section{RESUMO}

$\mathrm{O}$ artigo retrata as eminentes aptidões da EAD com o uso das TIC para o cumprimentos das metas do PNE. O referido artigo tem como objetivo analisar e descrever o papel das TIC no cumprimento das metas do PNE, eis que emerge o ensino hibrido como uma futura tendência pedagógica, para um melhor atendimento frente as TIC focado no cumprimento das metas do PNE, e o decreto 9.057/17 será de suma importância para concretizar de fato o que já vem acontecendo, que o forte crescimento da EAD. O presente trabalho trata-se de uma pesquisa bibliográfica e documental, que nos possibilita perceber que as TIC devera ser utilizadas de modo concreto e com responsabilidade pois a EAD cresce a longos passos com algumas dificuldades e deficiências, em alguns casos prejudicando a qualidade de oferta do ensino por falta de profissionais qualificados adequadamente para este novo modelo que é o ensino hibrido

PALAVRAS-CHAVE: PNE 1;TIC 2;EAD 3; HIBRIDO 4;DECRETO.

\section{INTRODUÇÃO}

A educação a distância tornou se realidade, e o número de alunos que aderem a esse tipo de ensino está estimado em mais de 1 milhão, hoje, somente no Brasil (BRASIL).

\begin{abstract}
Segundo o Censo de 2013, mais de $15 \%$ das matrículas em ensino superior são em cursos de ensino a distância (EAD). Atualmente, o País oferece mais de 1,2 mil opções nesta modalidade. Há equilíbrio na oferta dos cursos a distância entre os diferentes graus acadêmicos, havendo predomínio da participação das universidades privadas: $86,6 \%$ de participação. A licenciatura é o grau acadêmico que mais registra concluintes nesta modalidade de ensino (BRASIL).
\end{abstract}

Figurando a prática pedagógica em comunidades distantes dos grandes centro, fazendo com que a existência das ( TIC ) seja de fundamental importância para o crescimento e amplitude de acesso.

Em tal situação, o professor precisa saber que pode romper barreiras mesmo dentro da sala de aula, criando possibilidades de encontros presenciais e virtuais que levem o aluno a acessar as informações disponibilizadas no universo da sociedade do conhecimento. A rede 
informatizada contempla o registro e a manipulação dinâmica das informações escritas, sonoras e visuais combinadas. $\mathrm{O}$ docente precisa servir-se da informática como instrumento de sua prática pedagógica, consciente de que a lógica do consumo não pode ultrapassar a lógica da produção do conhecimento. Nessa ótica, o computador e a rede devem estar a serviço da escola e da aprendizagem. (MORAN, et al, 2008,PAG 78)

Para que haja esta amplitude e o crescimento a Educação a Distancia (EAD) é de suma importância para atingir a meta 12 do (PNE) de 2014 a 2024 sendo um plano Biênio .

Meta 12 Elevar a taxa bruta de matrícula na educação superior para $50 \%$ e a taxa líquida para 33\% da população de 18 a 24 anos, assegurando a qualidade da oferta.

E com tanta demanda a expansão da EAD eis que emerge novos profissionais no que diz respeito ao ensino e aprendizagem, disseminando diversas discussões em relação a pratica pedagógica dos profissionais de EAD. Nesse sentido: HENRIQUES,2008.

$\{\ldots\}$, a prática pedagógica nesta modalidade deve proporcionar momentos de reflexão e problematização das situações pedagógicas vividas, o que implica um exercício de crítica sobre sua atuação e sobre a atuação do outro nos espaços, tempos e contextos em que estão interagindo, pois, além do conteúdo que está sendo trabalhado, há a dimensão pedagógica, a qual precisa ser pensada e vivida de forma reflexiva (HENRIQUES, C. M. et al, 2008).

O exercício da docência no ensino superior, e principalmente na EAD, deve ser pautado na formação que vise uma aprendizagem mais significativa utilizando de estratégias metodológicas, com vista na mudança como o docente lidar com a informação, com a construção do conhecimento e as práticas pedagógicas.

LÉVY (2005) questiona:

Como manter as práticas pedagógicas atualizadas com esses novos processos de transação de conhecimento? Não se trata aqui de usar as tecnologias a qualquer custo, mas sim de acompanhar consciente e deliberadamente uma mudança de civilização que questiona profundamente as formas institucionais, as mentalidades e a cultura dos sistemas educacionais tradicionais e, sobretudo, os papéis de professor e de aluno (LÉVY, 2005, p.172).

É de senso comum a trivialidade das tecnologias da informação no cotidiano humano, pelo fato de que é possível encontrá-las em vários seguimentos da sociedade. A Educação 
passa a ser um desses segmentos com o fortalecimento das TIC, bem como da EAD. Contudo, sabe-se que essa integração entre Educação e TIC ainda está à margem do estado ideal, porém, novas evoluções são percebidas conforme essa realidade passa a ser uma necessidade para educadores e instituições de ensino que, por consequência, passam a revisar e (re)pensar suas praticas pedagógica. Um exemplo desses avanços é o ensino hibrido, que, segundo Bacich, Neto e Trevisani (2015):

Trata-se de um modelo de ensino que pressupõe o uso da tecnologia para o desenvolvimento das atividades dentro e fora da classe, em que o aluno é estimulado a buscar o conhecimento com a mediação do professor e da escola (BACICH, NETO, TREVISANI, 2015 p. 181)

Mediante esta forte tendência do ensino hibrido com base na "invasão " das tecnologias no cotidiano humano, precisam ser revistas e (re)pensadas suas praticas pedagógicas, que segundo SILVA,2000:

É preciso enfatizar: o essencial não é a tecnologia, mas um novo estilo de pedagogia sustentado por uma modalidade comunicacional que supõe interatividade, isto é, participação, cooperação, bidirecionalidade e multiplicidade de conexões entre informações e atores envolvidos. Mais do que nunca o professor está desafiado a modificar sua comunicação em sala de aula e na educação. Isso significa modificar sua autoria enquanto docente e inventar um novo modelo de educação (SILVA, 2000, p.15).

Antes dessas novas tendências se consolidarem como parte fundamental da Educação, é necessário que haja uma reformação dos professores, com vista no realce de suas habilidades dentro dos meios digitais de informação e comunicação

Fica evidente assim, a importância da atuação deste profissional que promoverá, em diferentes momentos, o convívio e a interatividade entre alunos e Instituição de ensino, assegurando um fluxo de comunicação bidirecional e, sobretudo, interativo, constituindo-se de um processo de co-participação, garantindo ao discente da EAD, um processo de ensino personalizado e adequado às suas necessidades acadêmicas. (Arbaad, 2009)

O objetivo deste trabalho é analisar e descrever o papel das TIC no cumprimento das metas do PNE, e com as mudanças que vem ocorrendo no campo educacional, justifica a realização da pesquisa, e sabendo que este novo modelo da proposta pedagógica tecnológica que é o ensino hibrido, vindo a se expandir cada vez mais no País. 


\section{HISTORIA DA EAD NO BRASIL E SUAS CONTRIBUIÇÕES.}

A EAD sendo muito antiga, mas os relatos anteriores ao século XX não foram registrados aqui no Brasil, tudo que se conhece é posterior.

Que de acordo com Alves, 2011,apud (MAIA e MATTAR,2007; MARCONCEN,2010; RODRIGUES,2010; SANTOS,2010) . Dados coletado e relacionado neste quadro, são episódios que se tornaram um marco na Historia da Educação a Distância no Brasil.

Quadro 1 - Historia da Educação a Distância no Brasil.

- 1904 - o Jornal do Brasil registra, na primeira edição da seção de classificados, anúncio que oferece profissionalização por correspondência para datilógrafo;

- 1923 - um grupo liderado por Henrique Morize e Edgard Roquette-Pinto criou a Rádio Sociedade do Rio de Janeiro que oferecia curso de Português, Francês, Silvicultura, Literatura Francesa, Esperanto, Radiotelegrafia e Telefonia. Tinha início assim a Educação a Distância pelo rádio brasileiro;

- 1934 - Edgard Roquette-Pinto instalou a Rádio-Escola Municipal no Rio, projeto para a então Secretaria Municipal de Educação do Distrito Federal. Os estudantes tinham acesso prévio a folhetos e esquemas de aulas, e também era utilizada correspondência para contato com estudantes;

- 1939 - surgimento, em São Paulo, do Instituto Monitor, o primeiro instituto brasileiro a oferecer sistematicamente cursos profissionalizantes a distância por correspondência, na época ainda com o nome Instituto Rádio $\neg$ Técnico Monitor;

- 1941 - surge o Instituto Universal Brasileiro, segundo instituto brasileiro a oferecer também cursos profissionalizantes sistematicamente. Fundado por um ex-sócio do Instituto Monitor, já formou mais de 4 milhões de pessoas e hoje possui cerca de 200 mil alunos; juntaram-se ao Instituto Monitor e ao Instituto Universal Brasileiro outras organiza- ções similares, que foram responsáveis pelo atendimento de milhões de alunos em cursos abertos de iniciação profissionalizante a distância. Algumas dessas instituições atuam até hoje. Ainda no ano de 1941, surge a primeira Universidade do Ar, que durou até 1944.

- 1947 - surge a nova Universidade do Ar, patrocinada pelo Serviço Nacional de Aprendizagem Comercial (SENAC), Serviço Social do Comércio (SESC) e emissoras associadas. O objetivo desta era oferecer cursos comerciais radiofônicos. Os alunos estudavam nas apostilas e corrigiam exercícios com o auxílio dos monitores. A experiência durou até 1961, entretanto a experiência do SENAC com a Educação a Distância continua até hoje;

- 1959 - a Diocese de Natal, Rio Grande do Norte, cria algumas escolas radiofônicas, dando origem ao Movimento de Educação de Base (MEB), marco na Educação a Distância não formal no Brasil. O MEB, envolvendo a Conferência Nacional dos Bispos do Brasil e o Governo Federal utilizou- -se inicialmente de um sistema rádio-educativo para a democratização do acesso à educação, promovendo o letramento de jovens e adultos;

Revista de Pesquisa Interdisciplinar, Cajazeiras, n. 2, suplementar, p. 1 - p. 11, set. de 2017. 
- 1962 - é fundada, em São Paulo, a Ocidental School, de origem americana, focada no campo da eletrônica;

- 1967 - o Instituto Brasileiro de Administração Municipal inicia suas atividades na área de educação pública, utilizando-se de metodologia de ensino por correspondência. Ainda neste ano, a Fundação Padre Landell de Moura criou seu núcleo de Educação a Distância, com metodologia de ensino por correspondência e via rádio;

- 1970 - surge o Projeto Minerva, um convenio entre o Ministério da Educação, a Fundação Padre Landell de Moura e Fundação Padre Anchieta, cuja meta era a utilização do rádio para a educação e a inclusão social de adultos. O projeto foi mantido até o início da década de 1980;

- 1974 - surge o Instituto Padre Reus e na TV Ceará começam os cursos das antigas $5^{\mathrm{a}}$ à $8^{\mathrm{a}}$ séries (atuais $6^{\circ}$ ao $9^{\circ}$ ano do Ensino Fundamental), com material televisivo, impresso e monitores;

- 1976 - é criado o Sistema Nacional de Teleducação, com cursos através de material instrucional;

- 1979 - a Universidade de Brasília, pioneira no uso da Educação a Distância, no ensino superior no Brasil, cria cursos veiculados por jornais e revistas, que em 1989 é transformado no Centro de Educação Aberta, Continuada, a Distância (CEAD) e lançado o Brasil EAD;

- 1981 - é fundado o Centro Internacional de Estudos Regulares (CIER) do Colégio Anglo Americano que oferecia Ensino Fundamental e Médio a distância. O objetivo do CIER é permitir que crianças, cujas famílias mudem-se temporariamente para o exterior, continuem a estudar pelo sistema educacional brasileiro;

- 1983 - o SENAC desenvolveu uma série de programas radiofônicos sobre orientação profissional na área de comércio e serviços, denominada "Abrindo Caminhos";

- 1991 - o programa "Jornal da Educação - Edição do Professor", concebido e produzido pela Fundação Roquete-Pinto tem início e em 1995 com o nome "Um salto para o Futuro", foi incorporado à TV Escola (canal educativo da Secretaria de Educação a Distância do Ministério da Educação) tornando-se um marco na Educação a Distância nacional. É um programa para a formação continuada e aperfeiçoamento de professores, principalmente do Ensino Fundamental e alunos dos cursos de magistério. Atinge por ano mais de 250 mil docentes em todo o país;

- 1992 - é criada a Universidade Aberta de Brasília, acontecimento bastante importante na Educação a Distância do nosso país;

- 1995 - é criado o Centro Nacional de Educação a Distância e nesse mesmo ano também a Secretaria Municipal de Educação cria a MultiRio (RJ) que ministra cursos do $6^{\circ}$ ao $9^{\circ}$ ano, através de programas televisivos e material impresso. Ainda em 1995, foi criado o Programa TV Escola da Secretaria de Educação a Distância do MEC;

- 1996 - é criada a Secretaria de Educação a Distância (SEED), pelo Ministério da Educação, dentro de uma política que privilegia a democratização e a qualidade da educação brasileira. É neste ano também que a Educação a Distância surge oficialmente no Brasil, sendo as bases legais para essa modalidade de educação, estabelecidas pela Lei de Diretrizes e Bases da Educação Nacional n ${ }^{\circ}$ 9.394, de 20 de dezembro de 1996, embora somente regulamentada em 
20 de dezembro de 2005 pelo Decreto $\mathrm{n}^{\circ} 5.622$ (BRASIL, 2005) que revogou os Decretos $\mathrm{n}^{\circ}$ 2.494 de 10/02/98, e n ${ }^{\circ} 2.561$ de 27/04/98, com normatização definida na Portaria Ministerial $\mathrm{n}^{\circ} 4.361$ de 2004 (PORTAL MINISTÉRIO DA EDUCAÇÃO a , 2010).

- 2000 - é formada a UniRede, Rede de Educação Superior a Distância, consórcio que reúne atualmente 70 instituições públicas do Brasil comprometidas na democratização do acesso à educação de qualidade, por meio da Educação a Distância, oferecendo cursos de graduação, pós-graduação e extensão. Nesse ano, também nasce o Centro de Educação a Distância do Estado do Rio de Janeiro (CEDERJ), com a assinatura de um documento que inaugurava a parceria entre o Governo do Estado do Rio de Janeiro, por intermédio da Secretaria de Ciência e Tecnologia, as universidades públicas e as prefeituras do Estado do Rio de Janeiro.

- 2002 - o CEDERJ é incorporado a Fundação Centro de Ciências de Educação Superior a Distância do Rio de Janeiro (Fundação CECIERJ).

- 2004 - vários programas para a formação inicial e continuada de professores da rede pública, por meio da EAD, foram implantados pelo MEC. Entre eles o Proletramento e o Mídias na Educação. Estas ações conflagraram na criação do Sistema Universidade Aberta do Brasil.

- 2005 - é criada a Universidade Aberta do Brasil, uma parceria entre o MEC, estados e municípios; integrando cursos, pesquisas e programas de educação superior a distância.

- 2006 - entra em vigor o Decreto ${ }^{\circ} 5.773$, de 09 de maio de 2006, que dispõe sobre o exercício das funções de regulação, supervisão e avaliação de instituições de educação superior e cursos superiores de graduação e sequenciais no sistema federal de ensino, incluindo os da modalidade a distância (BRASIL, 2006).

- 2007 - entra em vigor o Decreto $\mathrm{n}^{\circ}$ 6.303, de 12 de dezembro de 2007, que altera dispositivos do Decreto ${ }^{\circ} 5.622$ que estabelece as Diretrizes e Bases da Educação Nacional (BRASIL, 2007).

- 2008 - em São Paulo, uma Lei permite o ensino médio a distância, onde até $20 \%$ da carga horária poderá ser não presencial.

- 2009 - entra em vigor a Portaria $n^{\circ} 10$, de 02 julho de 2009, que fixa critérios para a dispensa de avaliação in loco e deu outras providências para a Educação a Distância no Ensino Superior no Brasil (BRASIL, 2009.

- 2011 - A Secretaria de Educação a Distância é extinta.

Fonte: ALVES pág87-90, 2011.

A educação a distancia se efetivou e ampliou a longos passos pelo país, e sabe se que surgiu no Brasil no final do século XIX, e agora no século XXI, para conseguir atingir as seguintes metas do PNE:

Meta 13 Elevar a qualidade da educação superior e ampliar a proporção de mestres e doutores do corpo docente em efetivo 
exercício no conjunto do sistema de educação superior para $75 \%$, sendo, do total, no mínimo, $35 \%$ de doutores.

Meta 14 Elevar gradualmente o número de matrículas na pósgraduação stricto sensu, de modo a atingir a titulação anual de 60 mil mestres e 25 mil doutores.

Meta 15 Garantir, em regime de colaboração entre a União, os estados, o Distrito Federal e os municípios, no prazo de um ano de vigência deste PNE, política nacional de formação dos profissionais da educação de que tratam os incisos I, II e III do art. 61 da Lei ${ }^{\circ}$ 9.394/1996, assegurando-lhes a devida formação inicial, nos termos da legislação, e formação continuada em nível superior de graduação e pós-graduação, gratuita e na respectiva área de atuação.

Meta 16 Formar, até o último ano de vigência deste PNE, 50\% dos professores que atuam na educação básica em curso de pós-graduação stricto ou lato sensu em sua área de atuação, e garantir que os profissionais da educação básica tenham acesso à formação continuada, considerando as necessidades e contextos dos vários sistemas de ensino.

BRASIL 2017

As TIC será de suma importância para o cumprimento destas metas, e será uma grande aliada na propagação de um novo modelo de educação.

Com o novo marco da EAD, que de acordo com o Decreto 9.057de 26 de Maio de 2017 terá uma nova política educacional brasileira que regulamenta a EAD. Assim sabendo que será vital designar normas mais rigorosas para garantir e assegurar a qualidade das Instituições no que se refere a projetos educacionais e infra estrutura, diretrizes de avaliações e aprendizagem dos alunos, e o mais importante que se tenha profissionais qualificados para dar maior suporte na EAD.

\section{A LEGISLAÇÃO E SEUS DESAFIOS.}

De acordo com a Lei de Diretrizes e Base da Educação (LDB) 9394 de 20 de Dezembro de 1996, eis que surge novos rumos e concretização de uma nova modalidade ensino, que segundo o Artigo 80, regulariza a criação dos programas de EAD, em todos os níveis e modalidades de ensino.

Conforme o Artigo 80: 
Art. 80. O Poder Público incentivará o desenvolvimento e a veiculação de programas de ensino a distância, em todos os níveis e modalidades de ensino, e de educação continuada.

$\S 1^{\circ}$ A educação a distância, organizada com abertura e regime especiais, será oferecida por instituições especificamente credenciadas pela União.

$\S 2^{\circ}$ A União regulamentará os requisitos para a realização de exames e registro de diploma relativos a cursos de educação a distância.

$\S 3^{\circ}$ As normas para produção, controle e avaliação de programas de educação a distância e a autorização para sua implementação, caberão aos respectivos sistemas de ensino, podendo haver cooperação e integração entre os diferentes sistemas.

$\S 4^{\circ}$ A educação a distância gozará de tratamento diferenciado, que incluirá:

I - custos de transmissão reduzidos em canais comerciais de radiodifusão sonora e de sons e imagens e em outros meios de comunicação que sejam explorados mediante autorização, concessão ou permissão do poder público;

II - concessão de canais com finalidades exclusivamente educativas;

III - reserva de tempo mínimo, sem ônus para o Poder Público, pelos concessionários de canais comerciais.

A referida Legislação foi dando corpo gradativamente e de acordo com as predileções distintas. Desde o inicio do século XX que a EAD vem sendo aplicado no Brasil, mas só se concretizou depois da terceira LDB que a EAD foi anuída, e para efetivação do Artigo 80 foi regulamentada pelo decreto 2.492 e 2.561 de 1988(delimitando que pelo menos $20 \%$ aulas ofertadas deve ser presencial), depois sendo os dois revogados pelo decreto 5.622 de 2005 que era referencial, e atualmente revogado pelo Decreto 9.057 de 25 de Maio de 2017. E com este Decreto só vem concretizar o que já vem acontecendo com a EAD.Conforme BRASIL:

A educação a distância cresce em ritmo mais acelerado que a presencial. Os dados do último Censo da Educação Superior, de 2015, mostram que enquanto o ensino presencial teve um crescimento de 2,3\% nas matrículas em 2015 em relação a 2014, o ensino a distância teve expansão de 3,9\%. Com isso, a educação a distância atinge a participação de $17,4 \%$ do total de matrículas da educação superior.

A rede privada concentra a maior parte das matrículas na modalidade (1.265.359) o que representa $90,8 \%$ do total de 1.393 .752 registradas em 2015. Apesar do aumento de $23,1 \%$ no número de concluintes do ensino a distância, índice maior que nos presenciais $(9,4 \%)$, muitos estudantes ainda deixam o curso sem concluí-lo. Nas instituições 
privadas, a taxa de evasão nos cursos a distância (EAD) é 35,2\%, taxa superior a evasão nos cursos presenciais, que é $27,9 \%$.

\section{CONSIDERAÇÕES FINAIS:}

De todas essas comprovações, pode-se concluir que as TIC no cumprimento das metas do PNE com o decreto 9.057/2017, atravessa um momento histórico na EAD, cheio de desafios que segundo BRASIL:

O intuito é ajudar o país a atingir a Meta 12 do Plano Nacional de Educação (PNE), que determina a elevação da taxa bruta de matrícula na educação superior para $50 \%$ e a taxa líquida em $33 \%$ da população de 18 a 24 anos. Na mesma linha, as IES públicas ficam automaticamente credenciadas para oferta $\mathrm{EaD}$, devendo ser recredenciadas pelo MEC em até 5 anos após a oferta do primeiro curso EaD.

Sendo assim, o referido trabalho aponta para o desejo de se fortalecer, as descorçoes entre o ensino convencional e o ensino hibrido e a regulamentação da EAD precisa ser discutida e ter um olhar mais atento para que tenha tudo muito bem elaborado garantindo a qualidade do ensino e aprendizagem, e tudo isto requer políticas publicas direcionadas para EAD. De acordo com a fala do secretario BRASIL:

Para o Secretário de Regulação e Supervisão da Educação Superior, Henrique Sartori, "esses quantitativos levam em consideração a preocupação que o Ministério da Educação tem em relação à qualidade das instituições, já que elas poderão criar mais polos conforme a qualidade que a instituição possuir e apresentar para a educação a distância. Então a criação dos polos fica condicionada à gradação da qualidade que as instituições do sistema possuem”.

E todas estas manobras que estão ocorrendo sem uma legislação especifica do MEC que de um norte ao ensino de EAD apesar de estarem fixando normas através de decretos, portarias e leis ministeriais com propósito e interesses políticos econômicos de alguns.

Mesmo com o novo decreto 9.057/2017 ainda existem muitas duvidas sobre como os cursos vão ser gerenciados, para não causar prejuízos no ensino aprendizagem do aluno.

THE ROLE OF INFORMATION AND COMMUNICATION

TECHNOLOGIES (ICT) IN COMPLIANCE WITH THE GOALS OF

THE NATIONAL EDUCATION PLAN (PNE) 


\section{ABSTRACT}

The article portrays the eminent skills of the EAD with the use of the ICT to the fulfillment of the goals of the PNE. The purpose of this article is to analyze and describe the role of ICTs in meeting the goals of the PNE. Hybrid education emerges as a future pedagogical trend, for better ICT service focused on meeting PNE goals, and the decree 9,057 / 17 will be of great importance in order to concretize in fact what has already been happening, that the strong growth of the EAD. The present work deals with a bibliographical and documentary research that allows us to perceive that ICT should be used in a concrete and responsible way since the EAD grows long steps with some difficulties and deficiencies, in some cases harming the quality of the offer Of teaching due to the lack of professionals adequately qualified for this new model which is hybrid teaching

KEYWORDS: PNE 1, ICT 2, EAD 3; HYBRID 4; DECREE

ALVES, Lucineia. Educação a distância: conceitos e história no Brasil e no mundo. Revista Brasileira de Aprendizagem Aberta e a Distância, v. 10, n. 1, 2011.

BACHIC, Lilian; TANZI NETO, Adolfo; TREVISANI, Fernando de Mello (org). Ensino Hibrido: personalização e Tecnologia na Educação. Porto Alegre: Penso. 2015.

BELLONI, Maria L. Educação a distância. 5. ed. Campinas: Autores Associados, 2008.

BRASIL, DECRETO $\mathbf{N}^{\mathbf{9}} \mathbf{9 . 0 5 7 ,}$ DE 25 DE MAIO DE 2017 Regulamenta o art. 80 da Lei no 9.394, de 20 de dezembro de 1996, que estabelece as diretrizes e bases da educação nacional.http://www.planalto.gov.br/ccivil_03/_Ato20152018/2017/Decreto/D9057.htm ACESSADO em 10/06/2017 BRASIL 2017 BRASIL, MEC atualiza regulamentação de EaD e amplia a oferta de cursos 21 de junho de2017http://portal.mec.gov.br/component/content/article?id=50451 ACESSADO EM 23/06/2017

BRASIL, Planejando a Próxima Década Conhecendo as 20 Metas do Plano Nacional de Educação http://pne.mec.gov.br/ ACESSADO EM 10/06/2017

BRASIL, LEI No 9.394, DE 20 DE DEZEMBRO DE 1996.

http://www.planalto.gov.br/ccivil_03/leis/L9394.htm BRASIL ACESSADO EM $13 / 06 / 2017$

G. S Abbad, T. Zerbini \& D. B. L. Souza Panorama das pesquisas em educação a distância no Brasil http://www.scielo.br/pdf/epsic/v15n3/a09v15n3

ACESSADO EM 20/05/2017 
HENRIQUES, Cecília Machado; AIMI, Daniela da Silva; GIORDANI, Estela Maris; FELDKERCHER, Nadiane. Implicações dos profissionais envolvidos nas práticas pedagógicas em educação a distância. Revista Paidéi@, UNIMES VIRTUAL, Volume 1, número 2, dez.2008. Disponível em:

http://revistapaideia.unimesvirtual.com.br. ACESSADO EM:_12/04/2017

INEP,Censo Educação Superior

2014http://download.inep.gov.br/download/superior/censo/2014/resumo_tecnico_censo _educacao_superior_2014.pdf ACESSADO EM 11/06/2017

LÉVY, Pierre. Cibercultura. São Paulo: Ed.34, 2005.

MORAN, José Manuel, MASETTO, Marcos Te BEHRENS,Marilda Aparecida • Novas Tecnologias e Mediação Pedagógica. São Paulo, Papirus Editora, 10ª Edição 2006

SILVA, M. Sala de aula interativa. Rio de Janeiro: Quartet, 2000. 